\title{
P02-014 - Consequences of Arginine 92 mutations in TNFR1
}

\author{
I Jéru ${ }^{1,2,3}{ }^{*}$, S Charmion ${ }^{4}$, E Cochet ${ }^{1}$, B Copin ${ }^{3}$, G Le Borgne ${ }^{2,3}$, P Cathebras ${ }^{4}$, J Gaillat ${ }^{5}$, P Duquesnoy ${ }^{3}$, S Karabina ${ }^{2,3}$, \\ $\checkmark$ Hentgen ${ }^{6}$, S Amselem ${ }^{1,2,3}$
}

From 7th Congress of International Society of Systemic Auto-Inflammatory Diseases (ISSAID)

Lausanne, Switerland. 22-26 May 2013

\section{Introduction}

TNFRSF1A is involved in a Mendelian autosomal dominant autoinflammatory disorder called TNFR-associated periodic syndrome (TRAPS). Most TNFRSF1A mutations are missense changes and, apart from those affecting conserved cysteines, their deleterious effect remains often questionable. This is especially true for the frequent R92Q mutation, which might not be responsible for TRAPS per se but represents a susceptibility factor to multifactorial inflammatory disorders.

\section{Objectives}

This study investigates TRAPS pathophysiology in a family exceptional by its size (13 members).

\section{Methods}

TNFRSF1A screening was performed by PCR-sequencing. Comparison of the 3-dimensional structure and electrostatic properties of wild-type and mutated TNFR1 proteins was performed by in silico homology modeling. TNFR1 expression was assessed by western blotting and ELISA in lysates and supernatants of HEK293T cells transfected with plasmids encoding wild-type and mutated TNFR1.

\section{Results}

A TNFRSF1A heterozygous missense mutation, R92W (c.361C $>$ T) perfectly segregated with typical TRAPS manifestations within the family $\left(\mathrm{p}<5.10^{-4}\right)$, and was associated with very high disease penetrance (0.9). Prediction of its impact on protein structure revealed local conformational changes and alterations of electrostatic properties. In addition, R92W leads to abrogation of the receptor shedding, whereas TNFR1-R92Q behaves like the wild-type receptor.

\section{Conclusion}

These data demonstrate the pathogenicity of a mutation affecting arginine 92, a residue whose involvement in inflammatory disorders is deeply debated. Combined with previous data on arginine 92 mutations, this study discloses an unusual situation in which different amino acid substitutions at the same position in the protein are associated with a clinical spectrum bridging Mendelian to multifactorial conditions.

\section{Disclosure of interest}

None declared.

\begin{abstract}
Authors' details
'Service de Génétique, APHP, Hôpital Trousseau, France. '2Université Pierre et Marie Curie-Paris6, France. ${ }^{3}$ UMR_S933, INSERM, Paris, France. ${ }^{4}$ Service de Médecine Interne, Centre Hospitalier Universitaire Saint-Etienne, SaintEtienne, France. ${ }^{5}$ Service des Maladies Infectieuses, Centre Hospitalier de la Région d'Annecy, Pringy, France. ${ }^{6}$ Centre de Référence des Maladies Autolnflammatoires, Centre Hospitalier de Versailles, Le Chesnay, France.
\end{abstract}

Published: 8 November 2013

doi:10.1186/1546-0096-11-S1-A121

Cite this article as: Jéru et al.: P02-014 - Consequences of Arginine 92 mutations in TNFR1. Pediatric Rheumatology 2013 11(Suppl 1):A121.

${ }^{1}$ Service de Génétique, APHP, Hôpital Trousseau, France

Full list of author information is available at the end of the article

(c) 2013 Jéru et al; licensee BioMed Central Ltd. This is an Open Access article distributed under the terms of the Creative Commons Attribution License (http://creativecommons.org/licenses/by/2.0), which permits unrestricted use, distribution, and reproduction in any medium, provided the original work is properly cited. 